\title{
Dolphin-Fisheries Interactions: An Increasing Problem for Mediterranean Small-Scale Fisheries
}

\author{
Geraci ML*, Falsone F, Scannella D, Sardo G and Vitale S \\ Institute for Biological Resources and Marine Biotechnologies, Italy
}

\section{ISSN: 2578-031X}

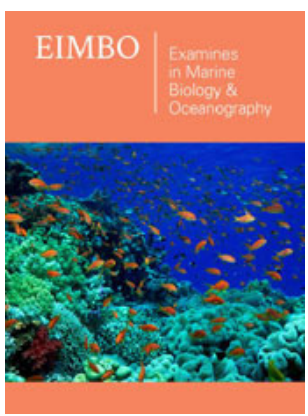

*Corresponding author: Geraci ML, Institute for Biological Resources and Marine Biotechnologies, Italy

Submission: 侮 June 04, 2019

Published: 制June 07, 2019

Volume 3 - Issue 1

How to cite this article: Geraci ML Falsone F, Scannella D, Sardo G and Vitale S. Dolphin-Fisheries Interactions: An Increasing Problem for Mediterranean Small-Scale Fisheries. Examines Mar Biol Oceanogr. 3(1). EIMBO.000552.2019.

DOI: 10.31031/EIMBO.2019.03.000552.

Copyright@Geraci ML, This article is distributed under the terms of the Creative Commons Attribution 4.0 International License, which permits unrestricted use and redistribution provided that the original author and source are credited.

\section{Opinion}

In the Mediterranean Sea, dolphin-fisheries interactions represent a 'burning' issue, with economic, social and ethical implications that further complicate fisheries management e.g. [1]. Indeed, net damage, reduction in catch value and decrease of total amount of fish caught are among the main negative impacts of dolphins on fisheries e.g. [2,3]. On the other hand, fisheries might cause dolphins unwanted catches determining mortal injury as well as behavior modification and reduction in reproductive rates [4,5]. Moreover, the increased overexploitation of the Mediterranean fish stocks [6], including important prey of dolphins [7], changed the food web dynamics, rising the interactions between dolphins and fisheries with potential threats for the present and future dolphin generations. Considering the essential role of dolphins on the equilibrium of the ecosystem e.g. [8] several international protection measures are in place, for example the Bern Convention and the Habitat Directive (92/43/EEC).

In Mediterranean Sea, the negative interactions with dolphin are mainly perceived by fishers involved in small-scale fisheries (SSF) e.g. [9], a sector became economically marginal and affected by market changes and/or socio-cultural factors [10]. In the last two decades a landing monitoring program on SSF in the "South of Sicily" (Geographical Sub Area, GSA 16) was carried out by Italian National Research Council (CNR) of Mazara del Vallo within European Data Collection Framework. Recently, during the monitoring activity an increasing alarm on the interaction between dolphin and SSF was raised from fishers for their economic losses due to gear and catch damages. Considering the poor and scattered data in the GSA16, a pilot survey based on fisher experience and knowledge was conducted. For this purpose, an ad-hoc questionnaire was drawn up to collect information about the negative impacts of dolphins on gear, catch as well as fisher's revenue.

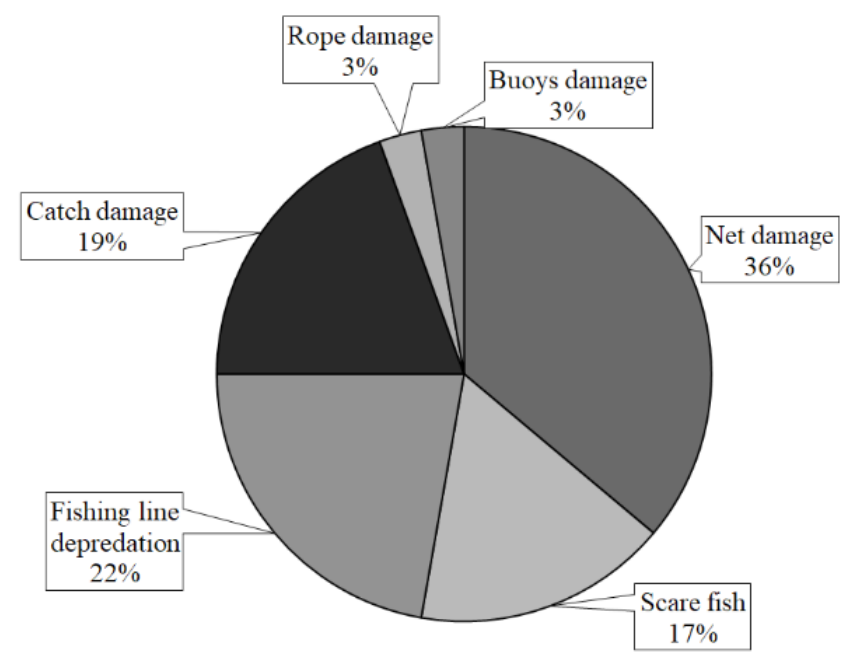

Figure 1: Pie chart of the main negative impacts of the dolphins on the Small Scale Fisheries (SSF)". 
A total of 37 questionnaires from fishers operating in the main harbors of the south of Sicily were collected. The data analysis showed as the main negative impacts during fishing operations was the net damage (36\%), followed by fishing line depredation (22\%) and catch damage (19\%) Figure 1. Regarding the economic aspects a mean loss of 13,000 (SD $\pm 11,229) € /$ year was estimated considering both gear damage and catch loss. Similarly, in the eastern coast of Sicily Monaco et al. [11], based on fisher's interviews, found a mean economic loss of 10,000 €/year for trammel net while for long-line up to $20,000 € /$ year. In the Mediterranean, different attempts were made to mitigate the interactions between dolphins and fisheries e.g. $[2,12]$ but, although an important scientific effort was done, the problem remaining unsolved. Specifically, in GSA16, Buscaino et al. [13] and Maccarrone et al. [14] tested acoustic deterrent devices (also known as pingers) mounted on monofilament bottom gill nets.

Both studies highlighted as pingers may reduce dolphins' depredations in terms of gear damage and loss of catch. Unfortunately, despite pingers are economically sustainable for the fishing company [14], during the CNR monitoring activities clearly came up fisher's reluctance to use this device. They strongly stated the low efficiency of the device due to the learning ability of the dolphins which relate the device to the presence of food causing the so called "dinner bell effect" [15]. Notwithstanding the huge literature on the dolphin-fisheries interactions in the Mediterranean Sea [9], uncertainties on economic loss as well as efficient technological solutions are still evident. Therefore, nowadays apart the historical data collection program for the main exploited stock, a systematic monitoring action plan on the dolphins-fisheries interactions seems of priority importance to collect reliable and robust data.

These data could be fundamental to develop specific Mediterranean management measures useful to mitigate the controversial dolphins-fisheries interactions as well as to estimate reasonable subsidies for fishers' economic losses. In the meantime, an increase in research funding should be provided in order to develop new technological solutions able to minimize the unwanted interactions. Unfortunately, in the Mediterranean Sea, formal commitments to protect cetaceans clash with geopolitical complexity, socio-economic and a generally poor political resolve [16]. The hope is that the auspicated monitoring action plan combined with new technological solution will contribute to balance legislation between commitments to protect dolphins and needs of fisheries.

\section{References}

1. Pardalou A, Tsikliras AC (2018) Anecdotal information on dolphinfisheries interactions based on empirical knowledge of fishers in the northeastern Mediterranean Sea. Ethics in Science and Environmental Politics 18: 1-8.
2. Gazo M, Gonzalvo J, Aguilar A (2008) Pingers as deterrents of bottlenose dolphins interacting with trammel nets. Fisheries Research 92(1): 7075.

3. Reeves RR, Read AJ, Notarbartolo di Sciara G (2001) Report of the workshop on interactions between dolphins and fisheries in the Mediterranean: Evaluation of mitigation alternatives. Doc SC/53/SM3 presented at the $53^{\text {rd }}$ Meeting of the International Whaling Commission, London, UK.

4. Bearzi G (2002) Interactions between cetacean and fisheries in the Mediterranean Sea. In: G. Notarbartolo di Sciara (Ed.), Cetaceans of the Mediterranean and Black Seas: State of knowledge and conservation strategies. A report to the ACCOBAMS Secretariat, Section 9, Monaco, p. 20.

5. Crosti R, Arcangeli A, Romeo T, Andaloro F (2017) Assessing the relationship between cetacean strandings (Tursiops truncatus and Stenella coeruleoalba) and fishery pressure indicators in Sicily (Mediterranean Sea) within the framework of the EU Habitats Directive. European journal of wildlife research 63(3): 55.

6. Colloca F, Scarcella G, Libralato S (2017) Recent trends and impacts of fisheries exploitation on Mediterranean stocks and ecosystems. Frontiers in Marine Science 4: 244.

7. Lleonart J (2005) Mediterranean and black sea. In: Review of the state of world marine fishery resources. FAO Fisheries Technical Paper 457, FAO UN, Rome, Italy, pp. 49-64.

8. Estes JA, Tinker MT, Williams TM, Doak DF (1998) Killer whale predation linking oceanic and nearshore ecosystems. Science 282(5388): 473-476.

9. Snape RTE, Broderick AC, Çiçek BA, Fuller WJ, Tregenza N, et al. (2018) Conflict between dolphins and a data-scarce fishery of the European Union. Human ecology 46(3): 423-433.

10. Maynou F, Morales NB, Cabanellas RM, Palmer M, García E (2013) Small-scale fishery in the Balearic Islands (W Mediterranean): A socioeconomic approach. Fisheries research 139: 11-17.

11. Monaco C, Cavallé M, Peri I (2019) Preliminary study on interaction between dolphins and small-scale fisheries in Sicily: learning mitigation strategies from agriculture. Calitatea 20(2): 400-407.

12. Brotons J, Munilla Z, Grau A, Rendell L (2008) Do pingers reduce interactions between bottlenose dolphins and nets around the balearic islands? Endangered Species Research 5: 301-308.

13. Buscaino G, Buffa G, Sarà G, Bellante A, Tonello AJ, et al. (2009) Pinger affects fish catch efficiency and damage to bottom gill nets related to bottlenose dolphins. Fisheries Science 75(3): 537-544.

14. Maccarrone V, Buffa G, Di Stefano V, Filiciotto F, Mazzola S, et al. (2014) Economic assessment of dolphin depredation damages and pinger use in artisanal fisheries in the archipelago of Egadi Islands (Sicily). Turkish Journal of Fisheries and Aquatic Sciences 14(1): 173-181.

15. Richardson WJ, Greene CG, Malme CI, Thomson DH (1995) Marine Mammals and Noise. Academic Press, San Diego, USA.

16. Portman M, Notarbartolo SG, Agardy T, Katsanevakis S, Possingham $\mathrm{H}$, et al. (2013) He who hesitates is lost: Why conservation in the Mediterranean Sea is necessary and possible now. Marine Policy 42: 270-279. 